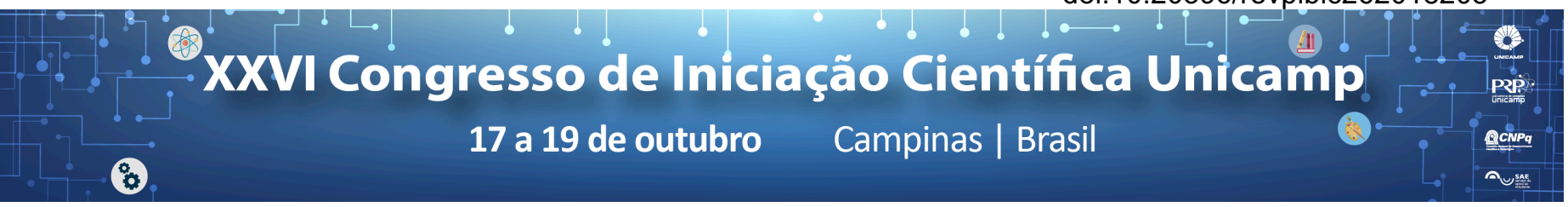

\title{
Avaliação da capacidade de mucoadesão de formulações comerciais em mucosa oral
}

\author{
Beatriz Trombetta Silva, Stephany Di Carla Santos, Michelle F.M.B. Leite.
}

\section{Resumo}

As formulações disponíveis para o uso tópico na mucosa oral adquiriram abrangência em sua prescrição e aplicação, especialmente, na área odontológica atual. Esse fato é consequente dos benefícios de redução do efeito adverso sistêmico e do aumento da biodisponibilidade do princípio ativo no sitio de ação dessa via administrativa. Porém, não há na literatura estudos que determinaram os parâmetros ideais de referência de mucoadesão para formulações de uso tópico em mucosa oral, que possam ser usados como parâmetro de comparação para o desenvolvimento de novos medicamentos. Dessa forma, o presente projeto teve como objetivo introduzir um estudo na literatura atual apresentando valores de referência das propriedades mucoadesivas (força de destacamento) em mucosa oral de suínos utilizando um equipamento analisador de textura. As seguintes formulações de uso tópico oral disponíveis comercialmente foram avaliadas: Benzotop ${ }^{\circledR}$ (Nova DFL), Omcilon-A em orabase ${ }^{\circledR}$ (Bristol- Myers Squibb), Xylocaína ® (AstraZeneca) e Mud Oral $®($ Eurofarma).

\section{Palavras-chave:}

Mucoadesão, odontologia, mucosa oral, estudo in vitro.

\section{Introdução}

Formulações visando o uso tópico na a cavidade oral devem apresentar boas propriedades mecânicas como baixa dureza e alta retenção no sítio de ação para garantir a entrega do princípio ativo. A capacidade de retenção em mucosa oral é avaliada pela sua propriedade mucoadesiva, a qual é essencial ser avaliada durante o desenvolvimento de uma formulação visando sua aplicação tópica em mucosa oral, a fim de se garantir sua eficácia clínica.

Um equipamento que é muito utilizado em diversos estudos publicados na literatura é chamado de analisador de texturas chamado de Texture Analyser TA/XT (Stable Micro Systems, UK). Este equipamento é capaz de medir a propriedade de mucoadesão em diferentes tipos de mucosa, através do uso de um dispositivo específico (sonda) conhecida como A/MUC.

Do nosso conhecimento, as formulações existentes no mercado para aplicação tópica em mucosa oral são o Omcilon-A em orabase $®$ (Bristol-Myers Squibb) e o Mud

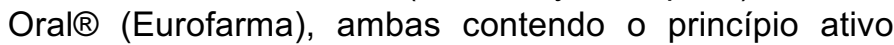
acetonida de triancinolona, um corticosteróide sintético. E também os anestésicos tópicos Xylocaína ${ }^{\circledR}$ (AstraZeneca) e Benzotop $®$ (Nova DFL), contendo os anestésicos locais lidocaína a $5 \%$ e benzocaína a $20 \%$, respectivamente.

Nesse sentido, o objetivo deste trabalho foi avaliar in vitro a capacidade de mucoadesão de formulações de uso tópico disponíveis comercialmente, visando a determinação de valores de referência para futuros estudos.

\section{Resultados e Discussão}

A Figura 1 mostra os gráficos de força de destacamento em função do tempo de contato das formulações com mucosa jugal de suínos. De uma maneira geral as formulações Oncilom e MudOral apresentaram melhor mucoadesão até $120 \mathrm{~s}$ de contato. Todas formulações apresentaram maior mucoadesão quando o tempo de contato foi aumentado. Nos tempos de contato

avaliados, a força de mucoadesão das formulações comerciais foi de 0,03 a $0,19 \mathrm{~N}$.

$30 \mathrm{~s}$

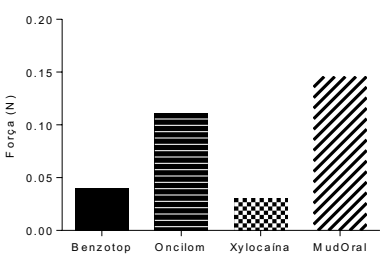

$120 \mathrm{~s}$
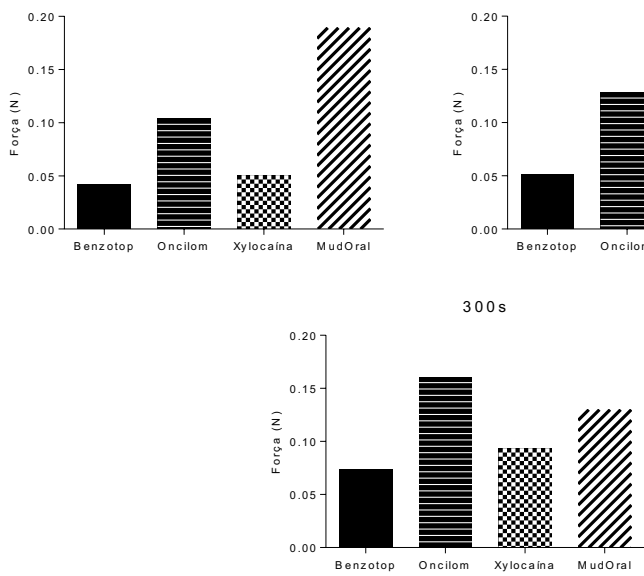

Figura 1. Média da força de destacamento $(\mathrm{N})$ em função do tempo de contato com mucosa jugal de suínos das formulações comerciais estudadas.

\section{Conclusões}

No geral, há uma relação diretamente proporcional e gradativa entre o tempo de contato da formulação com a mucosa e a força de destacamento. As formulações comerciais disponíveis apresentam força de destacamento na faixa de 0,03 a 0,19 N. Esse valores podem ser considerados ideais no desenvolvimento de novas formulações para uso tópico em mucosa oral.

\section{Agradecimentos}

Instituição de fomento: PIBIC/CNPq. 